\title{
Stage 0a Ureter Cancer AJCC v8
}

National Cancer Institute

\section{Source}

National Cancer Institute. Stage Oa Ureter Cancer A/CC v8. NCI Thesaurus. Code C140360.

Stage Oa includes: Ta, NO, MO. Ta: Papillary noninvasive carcinoma. NO: No regional lymph node metastasis. M0: No distant metastasis. (AJCC 8th ed.) 